\title{
LA PUBLICIDAD, FUENTE DOCUMENTAL PARA EXPLICAR PERMANENCIAS Y CAMBIOS EN LAS SOCIEDADES CONTEMPORÁNEAS
}

\author{
Amparo Moreno Sardà \\ amparo.moreno@uab.cat \\ Universitat Autònoma de Barcelona \\ Pedro Molina Rodríguez-Navas \\ pedro.molina@uab.cat \\ Universitat Autònoma de Barcelona
}

Recibido: 28-02-2012

Aceptado: 16-04-2012

\section{Resumen}

En este artículo planteamos que la publicidad comercial es un fenómeno fundamental en las sociedades contemporáneas y una fuente documental que puede arrojar luz para comprender las transformaciones históricas recientes. Y explicamos que el análisis de la publicidad comercial que aparece en diferentes medios de comunicación de masas y en distintos momentos históricos nos condujo a hacer una crítica del pensamiento académico androcéntrico que nos permitió clarificar los criterios metodológicos para analizar las aportaciones y limitaciones de los anuncios al conocimiento social. En la primera parte situamos la publicidad en este marco teórico; en la segunda, proponemos algunos criterios metodológicos para analizarla; y finalmente aplicamos estos planteamientos al análisis de anuncios extraidos de dos semanarios populares publicados en España en los años cincuenta y primeros sesenta del siglo XX.

Palabras clave: Publicidad, androcentrismo, fuente documental, relaciones sociales, movilidades sociales.

\begin{abstract}
In this article we consider that advertising is a fundamental phenomenon in contemporary societies and a source of records that can shed light in order to comprehend the historical changes recently. We also explain that the analysis of the commercial advertising that appear in different mass media and in different historical moments lead us to perform a criticism of the androcentric academic thought, which allowed us to clarify the methodological criteria in order to analyze the advertisements contributions and limitations for the social knowledge. In the first part we place advertising in this theoretical frame; in the second, we propound some methodological criteria to analyze it; finally, we apply this approaches to the advertisement analisys drew from popular weekly newspapers published in Spain in the 50's and early 60's of the $20^{\text {th }}$ Century.
\end{abstract}

Key words: Advertising, androcentrism, record source, social relations, social mobility. 


\section{Marco Teórico}

\subsection{La crítica al pensamiento académico andro-público-logo-céntrico, imprescindible para comprender la publicidad comercial en las sociedades contemporáneas.}

La publicidad comercial es un fenómeno fundamental en las sociedades contemporáneas y por tanto podemos considerarla también una fuente documental para comprender las transformaciones sociales recientes. Los anuncios constituyen un material muy rico que arroja luz sobre los cambios y las permanencias que se han producido en las relaciones entre mujeres y hombres de diferentes edades, procedencias, condiciones sociales, capacidades y necesidades..., tanto cuando actúan en los escenarios públicos como en los privados e incluso en la intimidad. Sin embargo, este material no se suele tener en cuenta de este modo porque el discurso académico está regido por un orden androcéntrico que no permite abarcar todos los aspectos que confluyen en la publicidad; es más, impone restricciones que impiden comprender la pluralidad, diversidad y complejidad de las relaciones sociales y de forma especial, al papel desempeñado por la publicidad comercial.

Cuando hablamos de las restricciones que impone el pensamiento académico androcéntrico no nos referimos solamente al silencio o la marginación de las mujeres, y tampoco a un enfoque de género masculino que excluye y menosprecia al género femenino. Estos aspectos constituyen solamente una parte de un problema que es más complejo ${ }^{1}$.

Por una parte, el pensamiento androcéntrico enfoca de forma preferente a los varones adultos de clases y pueblos dominantes en tanto que actores que ejercen el poder en los escenarios públicos, y menosprecia las actividades de la mayoría de mujeres y hombres en sus relaciones en los escenarios privados; precisamente, los escenarios en los que la publicidad comercial interviene de forma decisiva ya que se refiere a productos que se ofrecen para responder a las necesidades, aspiraciones y sueños de mujeres y hombres tanto en sus actuaciones cotidianas como en la representación de sus papeles públicos. Por tanto, la publicidad comercial sobrepasa el marco de análisis de un pensamiento que limita su atención a los actores de los escenarios públicos y especialmente a los de carácter político: desborda un enfoque que podemos definir como andro-público-céntrico.

Además, la publicidad comercial hace una representación simbólica de la realidad que también desborda al pensamiento académico. Ciertamente, la publicidad, como cualquier otra fuente, no es transparente: no refleja la realidad tal cual, sino que es el resultado de una elaboración al servicio de los intereses de quienes la han producido y financiado, para lo cual utiliza unas pautas de construcción simbólica de la realidad. Por tanto, no podemos utilizarla tal

\footnotetext{
${ }^{1}$ Sobre la crítica al orden androcéntrico del discurso académico y los rasgos que caracterizan esta explicación, ver Moreno Sardà (1986 y 1988). Y sobre las restricciones que el pensamiento androcéntrico impone a la comprensión de los medios de comunicación y la cultura de masas, ver especialmente Moreno Sardà (1998 y 2007).
} 
como se presenta. Pero tampoco podemos menospreciar lo que ofrece, o limitarnos a alabarla. Y si queremos utilizarla como fuente documental, hemos de identificar además de los intereses en juego, públicos y privados, los procedimientos que utilizan los publicitarios para construir los anuncios; y hemos de tener en cuenta que no se corresponden con los que gobiernan el pensamiento académico elaborado de acuerdo con la racionalidad androcéntrica, ya que apela a los sentimientos, al mundo afectivo que desde esa racionalidad se menosprecia como "irracional" porque no sigue sus propias reglas. Es decir, que la publicidad comercial sobrepasa también un pensamiento andro-público-logo-céntrico, de ahí que sea menospreciada e incluso ignorada.

En definitiva, para poder explorar, comprender y utilizar las aportaciones que la publicidad comercial puede hacer para elaborar una explicación histórica de las sociedades contemporáneas, es necesario realizar una crítica del pensamiento académico, y llevarla hasta la autocrítica, ya que éste es el enfoque que hemos asumido para incorporarnos a él como profesionales. Sólo así podremos obtener una visión más amplia en la que las actuaciones en los escenarios públicos aparezcan articuladas con las que se desarrollan en los privados, íntimos y marginales; y para que las construcciones simbólicas que apelan a la racionalidad puedan comprenderse en relación con otras racionalidades que gobiernan la sentimentalidad (Moreno Sardà, 1991).

Hemos de advertir que estas restricciones repercuten también en aquellos análisis que se centran en una parte del problema, el "género", si eluden un análisis de las relaciones sociales más amplio y complejo.

\subsection{El papel de la publicidad en las sociedades contemporáneas.}

La crítica-autocrítica a lo que el pensamiento académico androcéntrico incluye y excluye, valora positiva y negativamente, nos permitió formular otros paradigmas que definimos como no-androcéntricos para expresar que damos un sentido positivo a lo negado, pero no como algo superior, sino como algo existente y significativo; y para adoptar una posición distanciada del centro aunque a la vez también atenta al centro y a las articulaciones dinámicas entre centros y periferias. En estos paradigmas se basa la Historia de la Comunicación no-androcéntrica que propone enfocar la diversidad social de mujeres y hombres en sus actuaciones y relaciones, en escenarios públicos, privados, íntimos y marginales, y tanto las expresiones de la racionalidad como de la sentimentalidad ${ }^{2}$.

Este punto de partida nos ha permitido identificar algunas dimensiones de la publicidad comercial que consideramos fundamentales para poder utilizarla como fuente documental, que tienen que ver con los intereses a los que responde y con los procedimientos que utiliza para representar simbólicamente la realidad al servicio de esos intereses.

\footnotetext{
${ }^{2}$ Este recorrido puede seguirse a través de los textos recopilados en Moreno Sardà (2007).
} 


\subsubsection{A qué intereses responde la publicidad comercial}

La publicidad comercial es un elemento fundamental para la industria de la producción de bienes orientada por la lógica expansiva propia del sistema capitalista: da a conocer los productos en mercados más amplios que las zonas en las que se producen, difunde entre grandes cantidades de población el conocimiento de las prestaciones que ofrecen, y facilita así que cada vez más gente se interese por ellos y pueda decidir adquirirlos. Más aún, proclama y exalta sus ventajas fomentando el deseo de conseguirlos y consumirlos.

De este modo, la publicidad comercial pone en relación los intereses de quienes producen los bienes con las personas que buscan cubrir necesidades de distinto orden, y colabora a regular las relaciones entre oferta y demanda en el mercado de consumo. Y esto no sólo de forma abstracta sino muy concreta. La publicidad comercial explica, a veces de forma explícita y otras implícitamente, que en las sociedades contemporáneas, para conseguir los productos mediante los que se pueden satisfacer las necesidades básicas y no tan básicas, hay que disponer de dinero; indica, así, qué posibilidades tiene cada persona de obtener o no unos u otros productos; en consecuencia, informa de que estas posibilidades dependen del dinero del que dispone cada cual, porque lo recibe en concepto de salario o remuneración por el trabajo que hace, por el patrimonio de la familia de origen o porque lo ha acumulado. Y así, constituye una guía mediante la cual cada persona puede calcular qué bienes puede obtener de los que se ofrecen en el mercado, de cuáles puede disponer o no y cuándo; por tanto, qué necesidades puede cubrir o no según la valoración monetaria que merece en el mercado de trabajo o en función de los bienes que posee.

En cada anuncio confluye, por tanto, una red que relaciona oferta y demanda. Cada anuncio habla de los intereses de quienes producen bienes y de las necesidades de las personas, mejor, de las necesidades que la oferta dice que se pueden satisfacer adquiriendo productos en el mercado de consumo. Y pone de manifiesto en qué medida cada persona puede satisfacer qué necesidades según la valoración que merece en el mercado de trabajo. Los anuncios hablan, así, tanto de la producción como del consumo de los bienes y del trabajo necesario para disponer del dinero para satisfacer las necesidades, y generan expectativas sobre formas de vida alcanzables que determinan la voluntad de hacer para poseer siguiendo los modelos de confort y los signos que identifican a los grupos que acumulan más riqueza.

\subsubsection{Con qué procedimientos se representa simbólicamente la realidad en los anuncios al servicio de estos intereses}

Además de informar de los productos y las necesidades que se pueden cubrir con estos productos, además de regular las relaciones entre oferta y demanda en el mercado de consumo que repercute en el mercado de trabajo, la publicidad comercial construye una representación simbólica idealizada de estas relaciones, de los bienes que ofrece y de las necesidades que se pueden satisfacer con ellos. Transmuta el reino de las necesidades en un reino de placeres y 
felicidad al que se puede acceder mediante el dinero. Y esta representación, lejos de estar definida de una vez por todas en una imagen estática y lejana, incita siempre a ir más allá para alcanzar un paraíso que se sitúa no ya en la otra vida sino aquí en la tierra, y que sólo se puede disfrutar mediante la renovación constante del consumo de bienes en beneficio de una producción industrial también incesante. La publicidad actualiza, de este modo, la mitología bíblica del pecado original que condena a "crecer, multiplicarse y dominar la tierra" con dolor para recuperar un paraíso perdido, que está en la base de la lógica expansiva del capitalismo ${ }^{3}$.

Pero a diferencia del discurso religioso, oculta los sufrimientos imprescindibles para alcanzar la gloria: ignora los conflictos sociales y las confrontaciones bélicas que provoca esta lógica; sólo se interesa por la felicidad que proporciona la riqueza y elude mencionar que ésta se deriva del saqueo de otros pueblos y de las tensiones que genera esta actividad antihumana. Idealiza, así, a hombres y mujeres de los pueblos que se benefician del dominio de otros pueblos mediante una representación limpia de sangre, sudor y lágrimas.

Para comprender mejor esta representación simbólica de la realidad que ofrece la publicidad comercial, hay que tener en cuenta que constituye una pieza clave en las sociedades contemporáneas porque financia los medios de comunicación de masas y permite que éstos sean precisamente eso, masivos, que lleguen a las mayorías. Esto ha sido así desde el siglo XIX, cuando el primero de estos medios, la prensa escrita, que hasta entonces se dirigía a las minorías mediante suscripciones y con precios elevados, se orientó a sectores de población cada vez más amplios y para ello tuvo que rebajar el precio. La inserción de anuncios en las páginas de los periódicos ayudó a cubrir los costes de la producción de las noticias y facilitó que éstas llegasen al gran público. Y a medida que se desarrollaron nuevos medios, en el siglo $\mathrm{XX}$, la radio, la televisión y recientemente Internet, éstos han podido llegar también a grupos mayoritarios a precios reducidos porque han incorporado publicidad comercial. Ahora bien, estos medios y con ellos la publicidad que los financia se dirigen a los distintos grupos sociales que los publicitarios consideran que constituyen determinados mercados, públicos objetivos o "targets", porque disponen de diferentes recursos económicos con los que satisfacer sus necesidades o sueños.

En definitiva, podemos considerar los anuncios como teselas de un gran mosaico en las que se representan los productos que la industria del consumo masivo ofrece en nuestras sociedades como soluciones no sólo a las necesidades, sino también a las aspiraciones y los sueños de ir más allá y ser constantemente más y más. La publicidad comercial incita así a desear los productos y a desearlos de forma renovada una y otra vez. Por eso, en cada momento, el mosaico publicitario ofrece una representación simbólica de los bienes que se ofrecen en el mercado y prometen paraísos con las mejores condiciones de vida; y esta representación se renueva constantemente, anuncia mejoras y alimenta la necesidad de comprar nuevos productos para poder disfrutar de la felicidad; y promueve también la necesidad de ganar cada vez más dinero. Se trata por tanto de una representación simbólica de la realidad

\footnotetext{
${ }^{3}$ Sobre el sustrato mítico religioso del capitalismo y su vinculación especialmente con la tradición protestante y calvinista, ver Weber (1969) y Rybczynski (1986).
} 
que apela tanto al universo cognitivo y la racionalidad como al mundo afectivo de las aspiraciones y los sueños. Y para ello utiliza recursos que forman parte de la memoria colectiva y de las memorias asumidas por cada persona en sus itinerarios vitales.

Además, la publicidad comercial, en la medida en que financia los medios de comunicación de masas, los utiliza como plataformas desde las que opera para regular las relaciones entre la oferta y la demanda de productos, indicando a cada persona qué necesidades puede cubrir o no según la valoración monetaria que merece en el mercado, e incitándole a conseguir cada vez más dinero para poder alcanzar aquí en la tierra un paraíso del que sólo puede disfrutar consumiendo más y más. Esta representación simbólica de la publicidad complementa, por tanto, las otras representaciones simbólicas que ofrecen los medios de comunicación de masas en las que también se representan de forma más o menos dramática los infiernos de la marginación social, o en las que se argumenta y legitima el orden establecido, o se hacen propuestas para el ocio y la diversión...

De este marco teórico se desprenden los criterios metodológicos que han de guiar el análisis de los anuncios para evaluar qué representación ofrecen los cambios y las pervivencias en las relaciones entre oferta y demanda, y entre mujeres y hombres de diferentes edades, procedencias, condiciónes sociales, capacidades, necesidades...

\section{Criterios metodológicos para utilizar la publicidad comercial como fuente documental}

Hemos planteado que en cada anuncio confluye una red que relaciona oferta y demanda, y se hace una representación simbólica idealizada de los productos que ofrece la industria del consumo masivo y de las necesidades, aspiraciones y sueños de las personas potenciales compradoras. Por tanto, para utilizar la publicidad comercial como fuente documental hemos de interrogar a cada anuncio por los dos actores principales, por la oferta y la demanda, y hemos de examinar qué se dice de ellos y cómo se representan simbólicamente las relaciones que establecen. Esto significa que sólo podemos comprender, por ejemplo, los modelos de "género" teniendo en cuenta el marco de relaciones no sólo de "género" al que se refiere cada espacio publicitario. Vayamos por partes.

\subsection{Cómo se representa a la oferta}

En los anuncios publicados en los periódicos en el siglo XIX, se daban los datos que permitían identificar a las personas responsables de las empresas productoras de bienes. Sin embargo, a lo largo del siglo $\mathrm{XX}$ estos datos fueron desapareciendo de los espacios publicitarios ocultos bajo los nombres de las empresas, las marcas de los productos o los elementos gráficos con que se representan o logos, que son construidos para darlos a conocer, despertar el interés de los potenciales consumidores e identificar fácilmente los productos. Esto se debe en buena medida a que la representación de la oferta ha cambiado a medida que lo han 
hecho las entidades económicas, tanto por la organización de los propietarios del capital como por la gestión de las empresas.

Podemos decir, que la representación simbólica de las personas responsables de las empresas productoras de bienes se ha deshumanizado de manera que hoy resulta casi imposible identificar a quienes han provocado la actual crisis económica. Y este cambio hay que relacionarlo con la lógica de expandirse por mercados ya no sólo locales o nacionales, sino cada vez más amplios y lejanos, para llegar a más y más personas en cualquier lugar de la tierra, siempre que sean potenciales compradores; una lógica que está en la base en la transformación del capital en productos financieros que se negocian lejos del alcance de la mayoría de la población e incluso de los representantes políticos elegidos democráticamente.

Además, la oferta aparece representada especialmente por los productos que ofrece que, a su vez, son empaquetados y revestidos simbólicamente por una parte mediante envoltorios para facilitar su transporte, distribución y conservación, y también, para facilitar que sean identificados por parte de las personas que potencialmente pueden comprarlos y consumirlos. Esta envoltura simbólica responde, por tanto, no sólo a criterios pragmáticos, sino también estéticos e incluso éticos.

La publicidad, podemos advertirlo en cada espacio publicitario, constituye por tanto una fuente documental de gran interés para el conocimiento de las transformaciones de las empresas productoras de bienes, de su forma de organizarse y de las redes que han extendido hasta abarcar la actual sociedad global.

\subsection{Cómo se representa a la demanda}

Hemos visto que la publicidad comercial explica que en las sociedades contemporáneas hay que disponer de dinero para poder obtener los productos mediante los que se pueden satisfacer las necesidades básicas y no tan básicas, e indica así las posibilidades que tiene cada persona, según el dinero del que dispone por el patrimonio de su familia de origen, porque lo recibe como salario o remuneración por el trabajo que realiza, o porque lo ha acumulado. Por tanto, aunque la publicidad pretende llegar al mayor número de potenciales compradores, solamente se dirige a aquellas personas que disponen de dinero: quienes no disponen de dinero quedan excluidos del paraíso que representa la publicidad.

Esta cuestión es fundamental para clarificar a qué mujeres y a qué hombres interpela y para ello los representa como potenciales beneficiarios de este mundo paradisíaco. La publicidad no se dirige - por eso no representa simbólicamente - a cualquier mujer o a cualquier hombre, sino que solamente se interesa por - y representa a - las mujeres y los hombres que disponen de dinero suficiente para adquirir los bienes que se ofrecen en el mercado o, al menos, a aquellos que pueden esforzarse y conseguirlo; mujeres y hombres que no disponen de dinero no son tenidos en cuenta y no forman parte de los personajes que aparecen en el mosaico. 


\subsubsection{A qué mujeres y hombres se incluye y se excluye en los espacios publicitarios}

Por tanto, cada anuncio nos ilustra de esa distinción social fundamental que afecta a las personas, según tienen o no tienen dinero para comprar bienes. Y cuando lo utilizamos como una fuente documental para comprender la sociedad en la que se produce, hemos de tener en cuenta esta diferencia que afecta a las personas, según la clase social a la que pertenecen, sea por la familia en la que han nacido o por la posición social que han adquirido a lo largo de su trayectoria vital; y hemos de valorar no sólo las aportaciones que puede hacer sino también esta limitación, que habla de la persistencia de esta diferencia radical entre las personas, según disponen o no disponen de recursos para satisfacer necesidades fundamentales $\mathrm{u}$ otras construidas simbólicamente y asumidas por mujeres y hombres.

Pensemos en cualquier anuncio de esos paraísos por excelencia que proponen viajes en vacaciones, como el que reproducimos en la Imagen 1: "Puerto Rico. Si quieres playa, mejor

Imagen 1

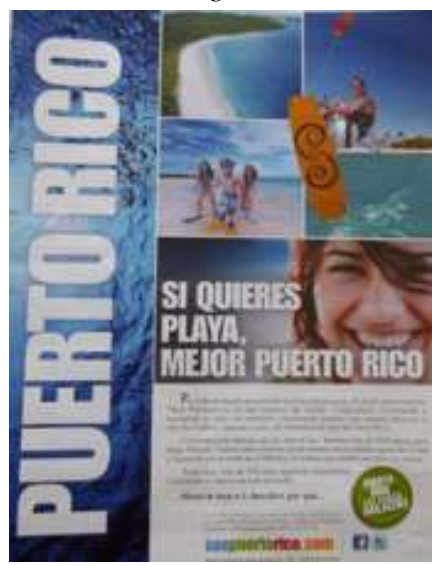

Fuente: El dominical Yo Dona, $18 / 02 / 2012$ Puerto Rico". En este espacio publicitario aparece tanto quien hace la oferta, la Oficina de Turismo de Puerto Rico en España, como quien representa la potencial demanda, un hombre, una mujer, dos niñas y un niño que disfrutan de la playa "más hermosa del mundo" según se expresa en sus rostros sonrientes. La explicación de la propuesta concluye: "Puerto Rico, más de 500 años regalando experiencias inolvidables a viajeros de todo el mundo. Ahora te toca a ti descubrir por qué...".

El análisis de lo incluido no puede hacernos olvidar lo excluido, para poder abarcar la lógica del conjunto: el trabajo requerido para conseguir el dinero necesario para poder disfrutar de ese "lujo"; el trabajo de otras muchas personas imprescindible para que la Oficina de Turismo de Puerto

Rico pueda ofrecer ese producto, los salarios y las condiciones laborales de la mayoría de las personas que se encargan de proporcionar el confort prometido también de ese otro grupo de personas más restringido que se beneficia de una demanda amplia de este producto y que, a su vez, recibirán ofertas para gozar de paraísos más exclusivos.

Queda claro por tanto que si utilizamos la publicidad como fuente documental hemos de tener en cuenta, ante todo, que sólo habla de una parte de la sociedad, de colectivos reducidos de mujeres, hombres, criaturas, incluso de momentos específicos que comparten determinadas posiciones sociales; que no podemos generalizar los resultados de nuestro análisis, ni limitarnos a los modelos de "género" sin más; pero sí, que los anuncios proporcionan indicios sobre aquellas otras personas que relegan a la cara oculta, y que por tanto hemos de tenerlas en consideración, so pena de quedarnos en la superficie construida para deslumbrarnos.

Con esta advertencia, ya podemos detenernos en la representación que se hace de mujeres y hombres en los anuncios. 


\subsubsection{Cómo se representa a mujeres y hombres incluidos: articulación de divisiones sociales en los modelos representados en los espacios publicitarios}

Recordemos. La publicidad sólo se dirige a aquellas personas que disponen de más o menos dinero para satisfacer sus necesidades fundamentales mediante el consumo de los bienes que ofrece el mercado; y las interpela, representándolas mediante un repertorio de modelos de comportamiento. Por tanto estos modelos no responden sólo a alguna de las divisiones sociales, ni al género, ni a la edad, ni a la etnia, raza o país de procedencia, ni a la clase social o el estatus... En todos los modelos que vemos en los anuncios - también en los excluidos convergen y se articulan todas las divisiones sociales, ante todo como hemos visto la clase social que define el nivel económico, pero también el sexo, la edad, el pueblo de origen y otras características que marcan las distintas posiciones sociales que ocupamos las personas.

Así, en el anuncio que hemos reproducido en la Imagen 1 aparecen explícitas las divisiones según la edad, el sexo y el color de la piel o etnia: en un primer plano, en el centro, un primer plano del rostro sonriente de una mujer adulta blanca; en un lugar no menos destacado, un hombre adulto blanco de cuerpo entero disfrutando sobre una tabla; y en una posición menos destacada, jugando en la arena a salir en la foto, dos niñas y un niño también blancos. Por tanto, está implícita la clase social que comparten las personas que disponen de posibilidades para poder pagar el producto que se ofrece.

Esto quiere decir que no podemos analizar los modelos que representa la publicidad teniendo en cuenta solamente el "género", so pena de incurrir en una visión no sólo simplista sino además distorsionada de las aportaciones que puede hacer la publicidad como fuente documental. Mujeres y hombres que aparecen en los anuncios de las distintas publicaciones o que acompañan a diferentes programas de televisión según franjas horarias no son homogéneos solamente por el género femenino o masculino: están modulados también por la edad, la clase social, el nivel económico, el estatus social y otros rasgos que no se pueden disociar en el análisis so pena de incurrir en visiones distorsionadas.

Es más, la relación entre los diversos modelos en los que se articulan todas las divisiones sociales, tiene que ver con las características de los escenarios sociales en los que las personas actúan y solventan sus necesidades, ya sean privados, públicos, íntimos, laborales o profesionales, de ocio o de negocio... De manera que en estas representaciones podemos advertir que se dan relaciones jerarquizadas e incluso antagónicas pero en el marco de complicidades fruto de beneficios compartidos. El análisis de los modelos ha de tener en cuenta, por tanto, los estereotipos que corresponden a los distintos modelos según las diferentes posiciones sociales que ocupan en cada escenario en el que se dan a la vez relaciones antagónicas y también de complicidad.

De hecho, la principal diferencia se da entre quienes son excluidos y quienes participan en el paraíso del consumo, como hemos visto, en relación con la clase social; y entre éstos, entre quienes disponen de más o menos recursos. 


\subsection{Persistencias y cambios en la oferta y la demanda: repercusiones de la lógica expansiva del consumo de masas transnacional en las movilidades sociales}

Ahora bien, según el diccionario de la Real Academia Española, estereotipo significa "imagen o idea aceptada comúnmente por un grupo o sociedad con carácter inmutable". Sin embargo, cuando analizamos los anuncios publicados en distintos medios de comunicación y en diferentes momentos históricos, advertimos que estos estereotipos no han permanecido inmutables, sino que se han ido modificando aunque han persistido algunos rasgos.

Así pues, la publicidad como fuente documental da cuenta de que en las sociedades contemporáneas se han producido cambios y procesos de movilidades sociales que han experimentado mujeres y hombres en sus trayectorias vitales, y explica cómo estos procesos han afectado a sus posibilidades de disponer de recursos para adquirir distintos tipos de bienes para solventar necesidades imprescindibles o no y, así, a sus posiciones en los escenarios sociales. Y también da cuenta de la relación entre estos cambios en las relaciones sociales, y los intereses de unos grupos vinculados al capital que, para producir más y más y alcanzar mercados más amplios, ha tenido que promover también que más gente pudiera disponer de más dinero y no sólo en metálico sino también en plástico y en forma de créditos para aplazar los pagos. En este marco se comprende el papel que ha adquirido el sistema financiero que ha provocado la actual crisis económica.

Podemos concluir, pues, que no se publican los mismos anuncios en los distintos medios de comunicación que se dirigen a públicos específicos, y además, que los espacios publicitarios se modifican y varían según contextos socioeconómicos y momentos históricos. Los productos que ofrecen, su precio, su presentación estética, las propuestas para incitar a su consumo y por tanto la ética que propugnan, ponen de manifiesto que persisten estereotipos en los que se articulan la clase social, el pueblo de origen o etnia, el sexo y la edad, y otras diferencias sociales; pero también, que estos estereotipos que corresponden a distintas posiciones no son estáticos: que se han modificado porque se han producido movilidades sociales.

Movilidades geográficas que han conducido a desplazamientos en las posiciones sociales de clase, y movilidades también en las posiciones atribuidas tradicionalmente dentro y fuera del espacio privado y en el espacio público, derivados de transformaciones en las formas de propiedad privada y pública de los bienes. Permanencias y cambios que se derivan de la dinámica expansiva de las sociedades capitalistas actuales y de las relaciones entre centros y periferias.

Lo examinamos a continuación a partir del análisis de algunos anuncios extraidos de las páginas de dos semanarios populares publicados en España a mediados del siglo XX.

Cuestiones de género: de la igualdad y la diferencia. No 7, 2012 - ISSN: 1699-597X - pp. 177-195 


\section{Análisis de anuncios publicados en los semanarios populares El Caso y Semana en los años 50 y primeros 60 del siglo XX en España}

Hemos elegido algunos anuncios publicados en dos semanarios populares, El Caso y Semana, para hacer un breve recorrido por la sociedad española de los años cincuenta y primeros sesenta, cuando todavía no se había implantado el consumo de masas: recordemos que hasta 1952 no se eliminó la cartilla de racionamiento para los alimentos, introducida desde 1939; que en 1959 se aprobó el Plan de Estabilización; y que en 1964 se puso en marcha el primero de los tres Planes de Desarrollo a los que se atribuyen cambios decisivos. En este periodo, numerosas mujeres y hombres que vivían en zonas rurales emigraron a las ciudades que, a partir de 1950, aglutinaron el 50\% de la población española, y una parte marchó también a buscar trabajo a otros países europeos. Los numerosos semanarios populares que se publicaron constituyen fuentes documentales de gran interés para comprender estas decisiones personales y colectivas.

El Caso, que se autodefinió como Semanario de sucesos, inició su publicación en mayo de 1952 y proporcionó sustanciosos beneficios a su propietario, Eugenio Suárez, que le permitieron lanzar otras publicaciones populares como Sábado Gráfico (1956), Velocidad (1960), Cine en 7 Días (1961), Discóbolo (1962), Burladero (1964)... En otros trabajos hemos considerado El Caso "una crónica de los procesos de movilidad social” ya que en sus páginas, "mientras las informaciones dramatizan las condiciones de vida de los grupos de población más marginados y pobres, la publicidad remite a las expectativas y los sueños y proporciona recetas para resolver estas situaciones o mejorar estas circunstancias" (Moreno Sardà, 1998: 125-127).

La revista Semana, que apareció en 1940 impulsada por la editorial Rivadeneyra, que publicaba Fotos (1937) y Domingo (1940), es una pieza destacada entre las numerosas publicaciones dirigidas especialmente a las mujeres tras la guerra civil, que juntamente con Dígame, de la Editorial Católica, ¡Hola! (1944), Diez Minutos (1951), Garbo (1953)..., ofrecían "una amplia crónica de sociedad del nuevo régimen con sus personajes, sus modelos idealizados, su suntuosidad en tonos sepia..." primero y luego en color (Moreno Sardà, 1998: 115).

Todas estas publicaciones contribuyeron a construir modelos idealizados en situaciones ideales que alimentaron los sueños y orientaron los esfuerzos que hicieron numerosas mujeres y hombres para mejorar sus condiciones de vida y las de sus hijos e hijas, y evitar la marginación social.

Los anuncios que hemos seleccionado de los ejemplares de El Caso de los años 50 y Semana de los 60 hablan, en primer lugar, de una serie de instrumentos que permitieron que hombres y mujeres realizaran trabajos en sus domicilios con los que pudieron completar sus ingresos. Un anuncio publicado en El Caso a partir de 1953 ofrecía la venta y el alquiler de "buenas máquinas de escribir, sumar, calcular", que podían interesar a hombres y mujeres. Y 
otros se dirigían específicamente a las mujeres. Un ejemplo es el que reproducimos en la

Imagen 2

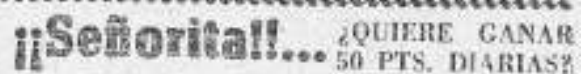
CON LA AGUJA MECANIZADS - PLERECTA v. MOBELA PROFRSIONAL, 1953 Raya mostroceios of muda en at manoje a mano as las

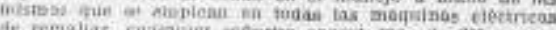

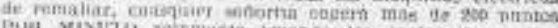

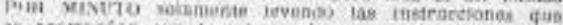

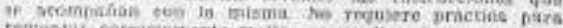

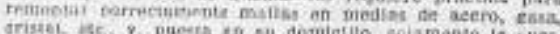

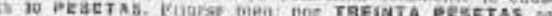
Fai

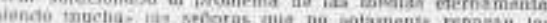

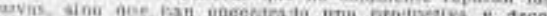

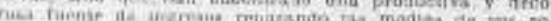

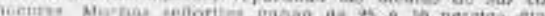

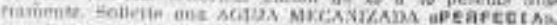

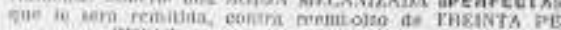

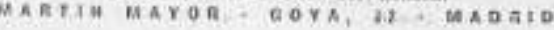

Fuente: El Caso no.90, 25/01/1954

Imagen 2, cuyo texto habla de forma clara de las condiciones de algunas mujeres: "¡i Señorita!!... ¿Quiere ganar 50 pts. diarias? Con la aguja mecanizada "Perfecta", modelo profesional 1953 cuya construcción se funda en el manejo a mano de las mismas que se emplean en todas las máquinas eléctricas de remallar, cualquier señorita cogerá más de 200 puntos por minuto solamente leyendo las instrucciones que se acompañan con la misma... Fijarse bien: por 30 pesetas se tiene solucionado el problema de las medias eternamente, siendo muchas las señoras que no solamente reparan las suyas, sino que han encontrado una productiva y decorosa fuente de ingresos reparando las medias de sus conocidas. Muchas señoritas ganan de 25 a 50 pesetas diariamente. Solicite una aguja mecanizada "Perfecta" que le será remitida, contra reembolso de treinta pesetas, por el distribuidor general...".

Otro ejemplo son los numerosos anuncios de máquinas de coser o de tricotar, utilizadas generalmente por las mujeres no sólo para las necesidades de la propia familia, sino también

Imagen 3

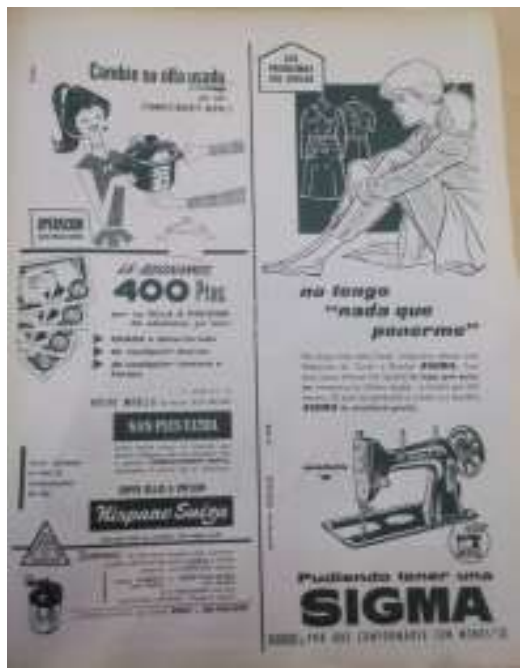

Fuente: Semana $n^{\circ}$.1040, 26/01/1960 para trabajar en su domicilio por cuenta ajena. En la Imagen 3 podemos ver uno publicado en un ejemplar de enero de 1960 en la revista Semana que forma parte de una serie que publicó la casa SIGMA en estos años, también en el $\mathrm{El}$ Caso y otros periódicos que, encabezados con el título "Los problemas del hogar" y concluyendo con el slogan "Pudiendo tener una Sigma, ¿por qué conformarse con menos?", resultan muy ilustrativos de las recetas que ofrecían a las amas de casa para promocionar la demanda de su producto. En este caso, la necesidad de la joven que puede aspirar a comprarla está clara: "No tengo nada que ponerme". Y la solución que propone la empresa también: "No diga más esta frase. Adquiera ahora una máquina de coser y bordar SIGMA. Con muy poco dinero Vd. tendrá la ropa que quiera siempre a la última moda y hecho por Vd. misma ( $\mathrm{Si}$ aún no aprendió a cortar y a bordar, SIGMA le enseñará gratis)”. Otros anuncios explican que SIGMA es la solución "cuando nace el niño", con "la ropa de los niños"... 
Ciertamente, las mujeres que no disponían de dinero o que lo conseguían mediante el trabajo doméstico asalariado, o en la prostitución, no están incluídas entre el público al que se dirigían los anuncios de estas revistas, a no ser que con su esfuerzo pueden llegar a pagar estos productos; y también las encontramos como protagonistas de las noticias de El Caso, como una de las peores amenazas de las amas de casa, las "criadas ladronas", o como chicas que han llegado a la ciudad pensando que podían hacer dinero fácil y que a menudo son víctimas de sus propios engaños. Los modelos de mujeres más recurrentes en estos anuncios son amas de casa con aire de jóvenes y modernas que aspiran a mejorar sus medios de vida y su estatus, aunque sus recursos sean escasos y tengan que completarlos cogiendo puntos de medias o cosiendo o tejiendo por encargo.

Otro grupo de anuncios que proliferaron en las páginas de El Caso especialmente a partir de mediados de los años 50, y que llenaron también otras publicaciones durante muchos años, informan de la importancia de la formación para que hombres y mujeres pudieran acceder a puestos de trabajo más cualificados que el de peón de la construcción o el servicio doméstico. La amplia oferta de cursos por correspondencia, la mayoría dirigidos a los hombres (maestro albañil, técnico de radio, automóvil... ofrecidos por el Instituto Americano, Diesel, $\mathrm{CCC}, \mathrm{CEAC}$ ), pero muchos dirigidos también a las mujeres, pone de manifiesto la existencia de una demanda.

En la Imagen 4 vemos un anuncio de la CCC dirigido a mujeres, publicado en El Caso en noviembre de 1957. El dibujo ratifica el título: “¡Feliz! Gracias al famoso curso Femina CCC de corte y confección. ¡También usted puede ser feliz si aprende a coser! Pero... no equivoque el camino, sólo la academia CCC le facilitará el camino seguro". En este mismo anuncio, este Centro de Cultura por Correspondencia de San Sebastián, con delegaciones en Madrid, Barcelona, y autorizado por el Ministerio de Educación Nacional, ofrece otros cursos: idiomas, cultura general, ortografía, solfeo, contabilidad... El camino es fácil: para recibir información, basta rellenar un cupón y enviarlo por correo gratis.

Otro elemento importante para poder obtener un puesto de trabajo es la imagen física de las personas, de ahí la importancia cada vez mayor de la ropa y también del propio cuerpo cuyo olor puede delatar falta de higiene, así como de los productos para mejorar una apariencia física

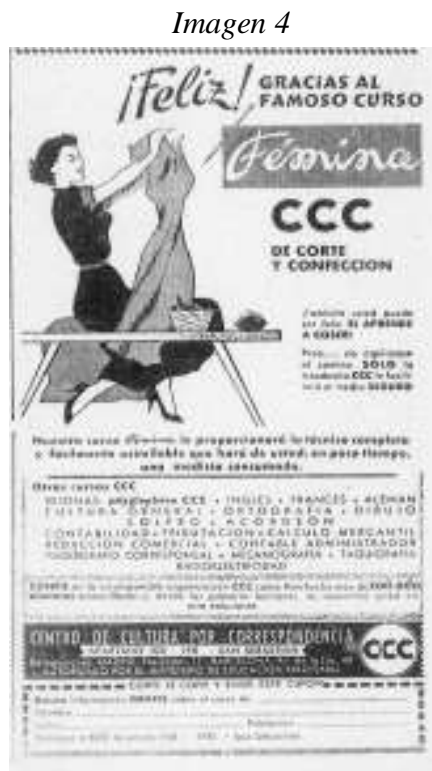

Fuente: El Caso $n^{\circ} .290,23 / 09 / 1957$ que se ha de adecuar especialmente a los modelos estilizados que difunde el cine (productos de belleza, tintes de canas, tratamientos para adelgazar, crecer, eliminar imperfecciones...). Y a la vez, los fármacos para calmar los dolores de pies, mareos... Tanto El Caso como Semana publican numerosos anuncios en los que se hacen las más variadas ofertas para satisfacer estas demandas, adecuados a distintos públicos. 
Un ejemplo es el anuncio publicado en El Caso en noviembre de 1957 (Imagen 5) que ofrece "el ajuar de París" pagándolo en "10 ó 15 mensualidades de plazo", que resulta "más barato a crétido en fábricas asociadas, que al contado en cualquier otro sitio": “¿Quiere usted mayor comodidad?”.

Cuatro viñetas explican los pasos que hay que dar: rellenar el cupón, depositarlo en correos, esperar tranquilamente, y recibir en casa el paquete con un obsequio de una pieza de batista blanca.

Otro ejemplo son los anuncios cada vez más abundantes y variados que proponen mejorar el aspecto físico. El de la Imagen 6 corresponde a un ejemplar de El Caso de 1955 que hace a las mujeres una propuesta recurrente: mejorar el busto. "Un busto magnífico en tres semanas".

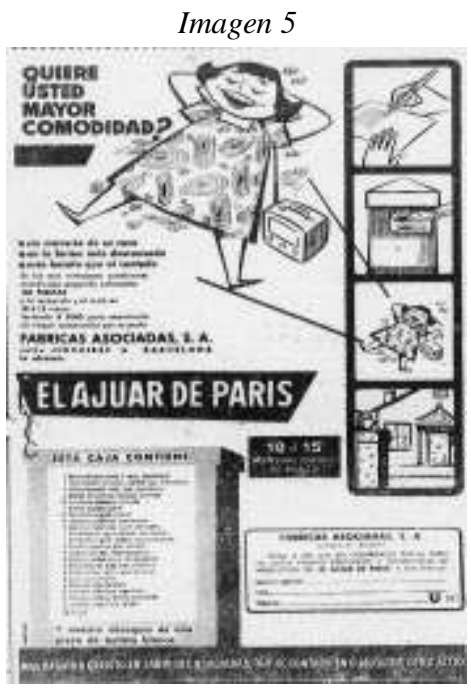

Fuente: El Caso no.286, 14/09/1957

IDEAL BUSTE propone tres fórmulas distintas: "desarrollar el busto pequeño...", "fortalecer el busto flácido...", y "reducir el busto demasiado desarrollado". Y propone hacer "una prueba fácil a nuestras expensas con la fórmula adecuada a vuestro caso".

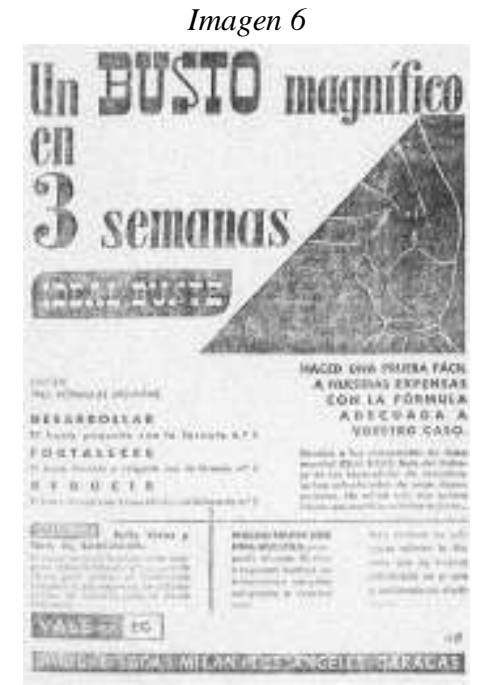

Fuente: El Caso no. 160, 29/05/1955

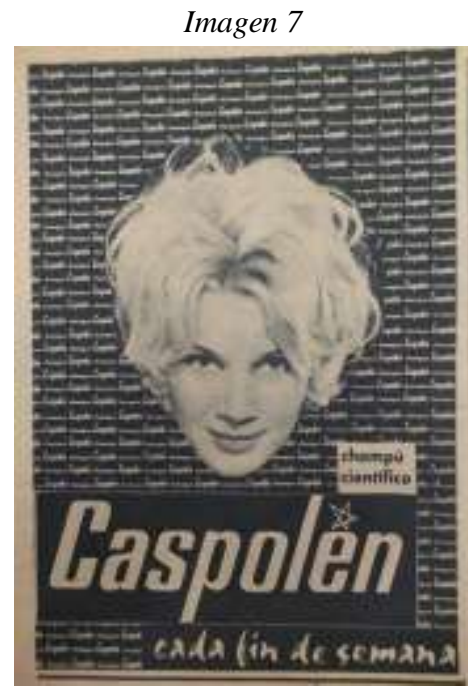

Fuente: Semana $n^{\circ} .1070,23 / 08 / 1970$

A mediados de los 70 el busto aparecerá desnudo. Más moderno, escueto y claro, es el anuncio extraido de un ejemplar de la revista Semana de agosto de 1960 (Imagen 7) en el que se oferta el "Champú científico CASPOLEN" con esta breve advertencia: "Cada fin de semana". 
Todo esto está en consonancia con disponer de una vivienda equipada con los más modernos objetos que hacen más fácil el trabajo doméstico y proporcionan un ambiente confortable que ha de ser, en primer lugar, limpio e higiénico. Los dos anuncios que

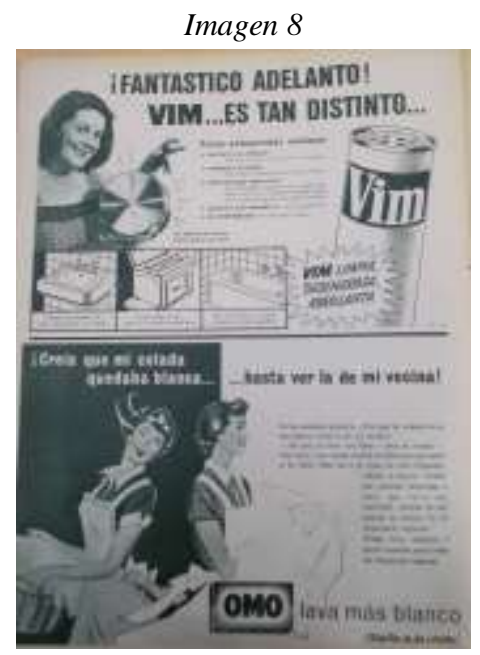

Fuente: Semana $n^{\circ} .1058,31 / 05 / 1960$ comparten una misma página del ejemplar de 24 de julio de 1962 de la revista Semana (Imagen 8) ofrecen dos productos para facilitar esta aspiración: en la parte superior, un “ ¡Fantástico adelanto! VIM... es tan distinto... Tiene estupendas ventajas. No raya al fregar... Produce espuma... Con envase práctico... Suave a las manos... Es perfumado..." Sirve para dejar brillantes la batería de cocina, la cocina y el baño. "VIM limpia, desengrasa y abrillanta". Y en la parte inferior, un detergente para lavar la ropa, "OMO lava más blanco", y "isalta a la vista!”, de manera que "Creía que mi colada quedaba blanca... hasta ver la de mi vecina...". En otro ejemplar de la misma época encontramos una composición similar que combina VIM con la pastilla de jabón LUX: "9 de cada 10 estrellas usan LUX", "Yo uso diariamente LUX... Sólo en LUX he encontrado la suavidad y la pureza que mi cutis necesita... Su nuevo perfume, ligero y delicado, le hace sentir una deliciosa sensación de frescura. Cuide usted también su cutis diariamente con LUX", dice Claire Bloom.

Una actividad fundamental en esta vivienda confortable es la alimentación que en estos años ha de ser no sólo saludable sino también económica, como se explica en el anuncio de "Leche condensada LA LECHERA" publicado en el ejemplar de 28 de junio de

Imagen 9

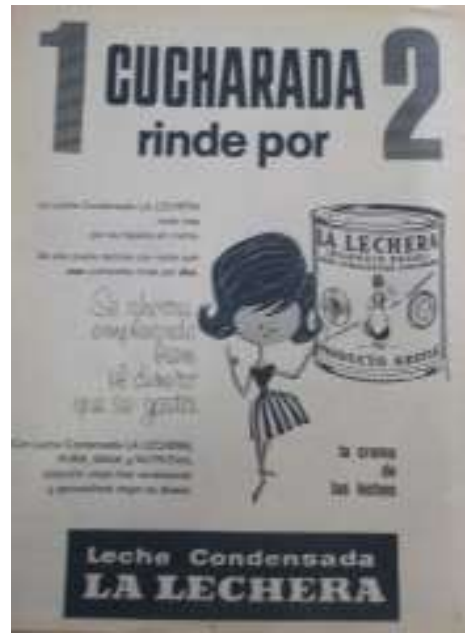

Fuente: Semana $n^{\circ}$.1062, 28/06/1960 1960 de Semana (Imagen 9): "1 cucharada rinde por 2", "La leche condensada La Lechera rinde más por su riqueza en crema... Se ahorra empleando bien el dinero que se gasta. Con la leche condensada LA LECHERA, pura, sana y nutritiva, obtendrá usted más rendimiento y aprovechará mejor su dinero".

Esta vivienda confortable ha de llenarse de objetos nuevos, como se explica en uno de los anuncios publicados en una página de un ejemplar de enero de 1960 de la revista Semana (Imagen 3) en la que, junto con el de la máquina de coser SIGMA que hemos analizado antes, aparece otro que propone: "Cambie su olla usada por una jcompletamente nueva!”... “Le abonamos 400 ptas. por su olla a presión de aluminio, ya sea usada o deteriorada, de cualquier manera, de cualquier tamaño o forma si requiere el nuevo modelo de olla de alta presión Non Plus Ultra... Super ollas a presión Hispano Suiza". 
Las características de este hogar quedan muy bien perfiladas en otro anuncio publicado en el ejemplar de Semana del 11 de setiembre de 1962, en una doble página que explica la historia de los rieles de cortinas Kirshner (Imagen 10). El largo y detallado texto en el que se explica este invento del señor Kirsh el año 1907, cuando estaba sin trabajo debido a la crisis económica en Estados Unidos de América, no tiene desperdicio.

En consonancia con estas posibilidades se propone también disponer de un medio de transporte propio, objeto idealizado, tal como vemos en este anuncio del ciclomotor TERROT ("De la France arrive...") publicado en el ejemplar de Semana de 19 de abril de 1960 (Imagen 11): un vehículo que para Imagen 10

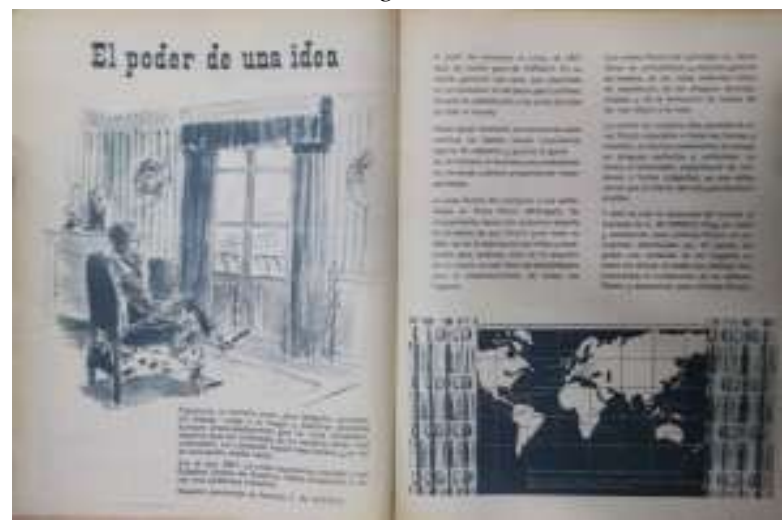

Fuente: Semana n $n^{\circ} .1177$, 10/09/1962 muchos hombres y mujeres fue fundamental para acudir al trabajo o incluso para trabajar, se representa como si fuera un juguete en manos de una joven alegre y despreocupada.

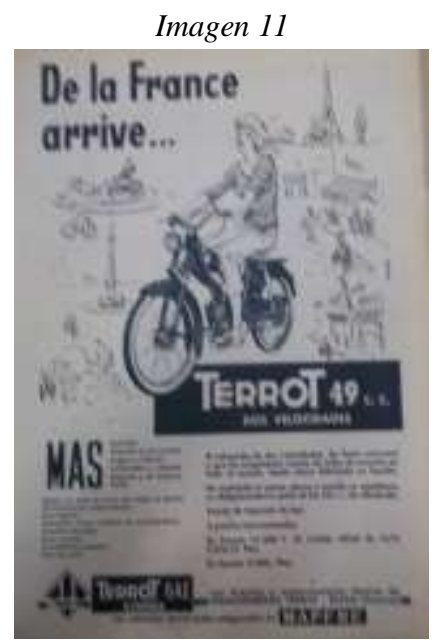

Fuente: Semana $n^{\circ} .1052$, $19 / 04 / 1960$

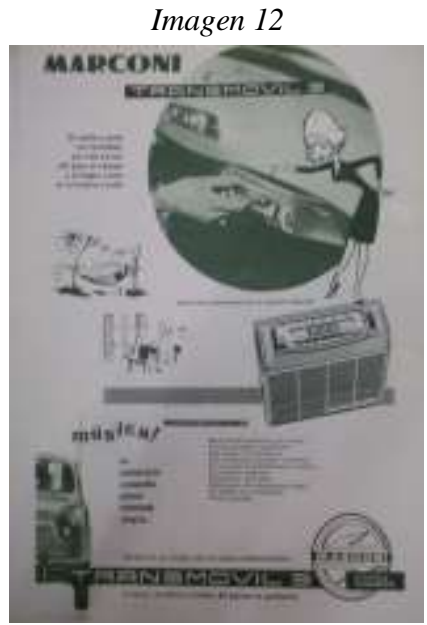

Fuente: Semana no.1170, $24 / 07 / 1962$

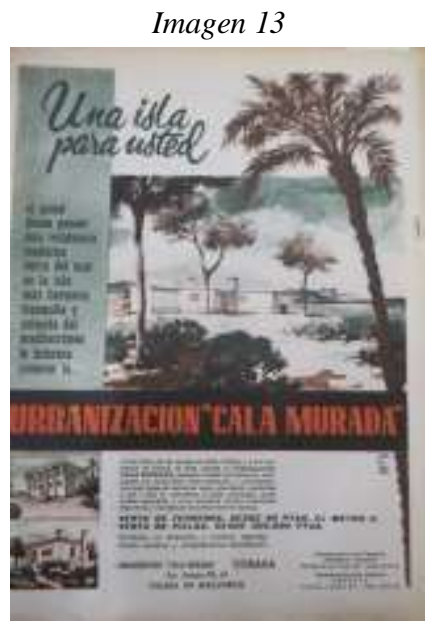

Fuente: Semana $n^{\circ} .1062$, $28 / 06 / 1960$

En la misma época, los coches también se equipan con objetos confortables, como el radio transistor MARCONI Transmovil que se anuncia en el ejemplar de Semana de 24 de julio de 1962 (Imagen 12): un aparato que "se quita y se pone con facilidad, por ello es tan útil para el campo y el hogar como en el mismo coche", donde proporciona "Musica! Es distracción, compañía, placer, intimidad, alegría"; "potente, duradero y bello: 45 países lo prefieren". 
Todo esto culmina en el paraíso que se ofrece en este anuncio de Semana de estos primeros años sesenta: "Una isla para usted" (Imagen 13): si desea "poseer una residencia moderna cerca del mar en la isla más hermosa, tranquila y soleada del Mediterráneo", en la "Urbanización Cala Murada" de Mallorca, puede hacerlo adquiriendo un terreno, desde 80 pesetas el metro cuadrado, o una villa, desde 200.000 pesetas. De este modo, se puede formar parte de esta "pequeña ciudad internacional".

En definitiva, mientras que algunos de los anuncios anteriores dan cuenta de que las ofertas de las empresas multinacionales que fabrican los modernos bienes de consumo que muestra el cine se están extendiendo por la sociedad española, éste propone formar parte del club selecto de la aldea global que puede disfrutar de vacaciones en segundas residencias e islas paradisíacas, antes de que se hayan producido los milagros que la literatura académica atribuye a los Planes de Desarrollo.

\section{Conclusiones y perspectivas}

El análisis de estos anuncios permite ratificar que la publicidad comercial juega un papel decisivo en nuestras sociedades, y que constituye una fuente documental de gran interés para explicar las pervivencias y los cambios que se han producido en la vida y las relaciones entre mujeres y hombres de distintas edades, clases sociales y pueblos de origen. Y que para poder tener en cuenta estas aportaciones es necesario realizar una crítica autocrítica del pensamiento académico andro-público-logo-céntrico, y no podemos quedarnos sólo en un análisis de "género".

Desde esta perspectiva, hemos dirigido o elaborado trabajos que han utilizado la publicidad para documentar los cambios en los modelos de representación de las relaciones entre mujeres y hombres (Sopeña: 1994; Quinayas: 2002; Vargas Carrillo: 2006), y que han resultado muy útiles como material didáctico para la docencia universitaria y para la formación básica de personas adultas (Moreno Sardà: 1998 y 2007; Molina: 1999). Especialmente relevante ha sido la elaboración de una guía didáctica ${ }^{4}$ que hemos aplicado desde 2007 en las asignaturas de Historia de la Comunicación que impartimos en las titulaciones de Periodismo, Comunicación Audiovisual y Publicidad y Relaciones Públicas, en la Universidad Autónoma de Barcelona (Moreno Sardà et al. 2008). Los resultados obtenidos nos han conducido a desarrollar una metodología en la que continuamos trabajando (Molina, Simelio e Ibarz, 2011).

\footnotetext{
${ }^{4}$ Este trabajo se pudo iniciar gracias a Proyecto de Innovación Docente Guias Didacticas de Historia de la Comunicación para experimentar las posibilidades de Internet 2 para la producción de contenidos de forma cooperativa e interactiva, dirigido por Amparo Moreno Sardà, que contó con una ayuda de la Universidad Autónoma de Barcelona.
} 
Estos y otros ingredientes permiten ver la posibilidad de elaborar algún día una explicación de las transformaciones históricas contemporáneas desde un enfoque noandrocéntrico, esto es, plural y en red, que permita articular conocimientos expertos con conocimientos derivados de las experiencias cotidianas; una explicación en la que las aportaciones personales y los medios de comunicación de masas, entre ellos la publicidad, constituirán fuentes documentales fundamentales para modificar el enfoque androcéntrico hoy predominante en el mundo académico. En definitiva, para llevar a cabo la necesaria revolución científica de las Ciencias Humanas y Sociales (Moreno Sardà: 2012), fruto de hacer visibles y considerar normales campos hasta ahora excluidos, menospreciados como insignificantes e ignorados como "anómalos”, en la terminología de Kuhn (Kuhn: 1962).

\section{Bibliografía}

- Kuhn, Thomas S. (1962): La estructura de las revoluciones científicas. Breviarios del Fondo de Cultura Económica: Madrid.

- Molina Rodríguez-Navas, Pedro (1999): “La prensa del corazón: un recurso para conocer los medios y explorar el mundo". En Diálogos. Educación y formación de personas adultas, 17, pp. 65-69.

- Molina Rodríguez-Navas, Pedro; Simelio solà Núria; Ibarz Gelabert, Jordi (2011): "Análisis de contenido del discurso audiovisual aplicado a la ficción televisiva y cinematogràfica como fuente de estudio para el conocimiento del pasado reciente". En $l^{e r}$. Congreso Nacional de Metodología de la Investigación en Comunicación. Investigar la comunicación en España: proyectos, metodologías y difusión de resultados. Asociación Espanyola de Investigación de la Comunicación, Universidad Rey Juan Carlos. Madrid, 1314 de abril de 2011, pp. 205-218.

- Moreno Sardà, Amparo (1986): El arquetipo viril, protagonista de la historia. Ejercicios de lectura crítica no-androcéntrica. Barcelona: LaSal.

. (1988): La otra 'Politica' de Aristóteles. Cultura de masas y divulgación del arquetipo viril. Barcelona: Icaria.

. (1991): Pensar la historia a ras de piel. Barcelona: Ediciones de la Tempestad

. (1998): La mirada informativa. Barcelona: Bosch.

. (2007): De qué hablamos cuando hablamos del hombre. Treinta años de crítica y alternativas al pensamiento androcéntrico. Barcelona: Icaria.

. (2010): "La revolución científica de las humanidades y las ciencias sociales: 
aportaciones y limitaciones de los estudios de género". Pronunciado en el Curso: Mujeres y Universidad: Cien años de historia (1910 - 2010), Organizado por el Seminario Interdisciplinar de Estudios de la Mujer (SIEM) de la Universidad de Zaragoza.

. (2012): “Aportaciones que podemos hacer las mujeres a la revolución de las Ciencias Humanas y Sociales para construir un humanismo plural en la era digital". En: Carmen Cortés Zaborras; $\mathrm{M}^{\mathrm{a}}$ Isabel Morales y $\mathrm{M}^{\mathrm{a}}$ Teresa Vera (coord.): Actas de Ponencias y Resúmenes. Málaga: Del Planeta Rojo Ediciones, pp. 13-31.

- Moreno Sardà, Amparo et al. (2008). “Guías didácticas de historia de la comunicación para experimentar las posibilidades de Internet para la producción de contenidos de forma cooperativa e interactiva". El canvi en la cultura docent universitària. $V$ congrés internacional docència universitària $i$ innovació. CIDUI, Congrès Internacional Docència Universitària i Innovació, Lleida, edición digital (CD), pp. 1-30.

- Quinayas, Gloria (2002), El Caso, Semanario de sucesos. Una crónica de los procesos de movilidad social durante la dictadura de Franco. Tesis de Licenciatura leida en el Departamento de Periodismo y Ciencias de la Comunicación de la Universidad Autónoma de Barcelona, inédita.

- Rybczynski, W. (1986): La casa. Historia de una idea. Madrid: Nerea.

- Sopeña, A. (1994). "La publicitat com a font documental per a la història comtemporània. El Hogar y la Moda (1913-1931)". Gazeta, 1, pp. 359-369.

- Vargas Carrillo, M M Soledad (2006), Estilos de vida, ética y estética en los dominicales de los diarios ABC, La Vanguardia y El Pais (1974-1999). Tesis doctoral leida en el Departamento de Periodismo y Ciencias de la Comunicación de la Universidad Autónoma de Barcelona. También [en línea], Disponible en: http://www.tdx.cat/handle/10803/4194 [12/01/2012].

- Weber, M. (1969): La ética protestante y el espíritu del capitalismo, Barcelona: Península. 